\title{
UNIVERSO DAS REPRESENTAÇÕES EM LINA BO BARDI: REPRESENTAÇÃO NÃO-TÉCNICA DA ARQUITETURA
}

UNIVERSE OF LINA BO BARDI REPRESENTATIONS: NON-TECHNICAL REPRESENTATION OF ARCHITECTURE

\section{SANTANA, LIVIA FERREIRA}

Mestre em Arquitetura e Urbanismo pela Universidade de Brasília, UNB, Docente do Instituto Federal de Educação, Ciência e Tecnologia de Goiás -

Campus Anápolis, arqliviasantana@gmail.com

\section{RESUMO}

A comunicação é uma das fases necessárias para completar o processo de desenvolvimento do projeto, visto que é através dela que o profissional apresenta suas ideias ao usuário. Partindo desse entendimento, o principal objetivo deste artigo é verificar a comunicabilidade de representações gráficas, ou seja, a sua compreensão pelos usuários, avaliando como a comunicação visual ajuda no diálogo profissional-clientes e quais recursos de representação ajudam na veiculação da mensagem. Sua finalidade é mostrar modos simples de representar graficamente o trabalho do arquiteto (traduzindo projetos arquitetônicos em desenhos esquemáticos e croquis), em especial as representações não-técnicas, que podem facilitar a comunicação dos profissionais de arquitetura com clientes ou usuários. Metodologicamente 0 trabalho utiliza pesquisa bibliográfica e estudo de caso como bases para análise da obra de Lina Bo Bardi, abordando elementos característicos do seu desenho como: volume, profundidade, proporção, opacidade, transparência e outros símbolos gráficos que podem auxiliar na comunicação da proposta projetual. Entre os principais resultados obtidos destaca-se que o desenho, quando representado de maneira clara e objetiva, permite uma comunicação eficiente entre o profissional e o cliente, e que o uso de elementos gráficos simples consegue expressar adequadamente os interesses e significados inerentes ao processo do projeto.

PALAVRAS-CHAVE: representação gráfica; comunicação; linguagem verbal; imagem visual.

\section{ABSTRACT}

Communication is one of the stages needed to complete the projection process, since it is through it that the professional presents its ideas to the user. Bases on this comprehension, the main objective of this article is to verify the communicability of graphic representations, that is, their comprehension by the users, evaluating how visual communication helps the dialogue professional-clients and which representations resources helps in the transmission of the message. Its purpose is to show simple ways to graphically represent the architect's work (translating architectural designs into schematic drawings and sketches), especially non-technical representations that can facilitate the communication of architecture professionals with clients or users. Methodologically the work uses bibliographic research and case study as bases to analysis Lina Bo Bardi's professional work, addressing characteristic elements of her drawing such as: volume, depth, proportion, opacity, transparency and others graphic symbols that can support the design propose communication. Among the main results obtained, it is worth highlighting that the design, when represented in a clear and objective way, allows an efficient communication between the professional and the client, and that the use of simple graphic elements can adequately express the interests and meanings inherent in the project process.

KEYWORDS: graphical representation; communication; verbal language; visual image. 


\section{INTRODUÇÃO}

O presente artigo trata da linguagem gráfica no processo de criação e na tradução do projeto, ou seja, em sua comunicação. $O$ interesse por este estudo decorre da dificuldade dos profissionais arquitetos se comunicarem com seus clientes, uma vez que a linguagem gráfica utilizada pelos primeiros (geralmente técnica e sofisticada) nem sempre é compreendida pelos segundos, considerados leigos no assunto (LARA, MARQUES, 2003).

A linguagem gráfica é um instrumento de intenso uso pelos profissionais das áreas de projeto, desde a concepção inicial da proposta até a sua execução final, sendo entendida como uma ferramenta básica para o desenvolvimento de projetos arquitetônicos. Além do desenho técnico, para auxiliar na representação gráfica de uma proposta projetual o arquiteto ainda utiliza alguns recursos adicionais, tais como, diagramas, esboços, desenhos, mapas, gráficos, anotações técnicas, e outros meios, que complementam a atividade (BORGES, NAVEIRO, 2001), os quais auxiliam tanto na etapa de concepção quanto, posteriormente, em sua comunicação, ou seja, na tradução do projeto em desenvolvimento para outras pessoas, especialmente o cliente. Tais representações gráficas adicionais também ajudam o profissional a visualizar possíveis problemas, detalhar algum aspecto importante do objeto arquitetônico durante a fase inicial, criar alternativas estruturais, buscar soluções para questões especificas, enfim, fazem parte da criação e concepção do projeto.

Nesse campo, um fator importante a ser discutido (e um dos objetivos desse artigo) é a comunicabilidade dessa mensagem, ou seja, a tradução do projeto para o cliente por meio da comunicação e o nível de compreensão que a mensagem gráfica consegue alcançar quando analisada pelo observador. Note-se que, neste caso, o desenho tem como objetivo tanto proporcionar o entendimento da proposta do arquiteto, como também facilitar o diálogo entre o profissional e o usuário. Assim, além da representação e suas potencialidades, é importante analisar o meio em que a mensagem é transmitida ao cliente (tais como: croquis a mão, ilustrações, perspectivas, maquetes eletrônicas ou modelos físicos) e as características desses meios de comunicação e projetação (cores, formas, perspectivas, ou seja, grafismos que representam visualmente o projeto).

Elaborado a partir deste entendimento geral, esse texto abordará o universo das diferentes representações gráficas não-técnicas, tendo como base a linguagem gráfica de Lina Bo Bardi, arquiteta formada pela Faculdade de Arquitetura da Universidade de Roma-Itália e posteriormente radicada no Brasil. Além de produções arquitetônicas nos dois países, a arquiteta também participou de outras manifestações culturais, como teatro, cinema, artes plásticas, desenho de mobiliário e outros, de modo que suas obras englobam desde o design e a moda até projetos urbanísticos (ver BARDI, 1993). Dentre suas produções arquitetônicas, destacam-se: o Museu de Arte de São Paulo (MASP), que é uma das obras mais conhecidas de Lina Bo Bardi; Instituto Pietro Maria Bardi (ou Casa de Vidro); Casa da Cultura (Recife); Igreja do Espírito Santo do Cerrado (Minas Gerais); Museu de Arte da Bahia; Teatro Oficina e SESC Pompéia (ambos em São Paulo).

Além dessa introdução, este texto está estruturado nos itens: Concepção e representação gráfica do projeto; Meios para comunicar a imagem; Análises de representações gráficas em Lina Bo Bardi; Considerações finais.

\section{CONCEPÇÃO E REPRESENTAÇÃO GRÁFICA DO PROJETO}

Para a concepção e representação de um projeto, o profissional geralmente utiliza croquis, perspectivas, gráficos, anotações técnicas, diagramas, entre outros, que são representações externas, utilizadas apenas para registro das ideias, ou seja, como informações auxiliares da memória que facilitam a concepção (BORGES, NAVEIRO, 2001). Portanto, o desenho corresponde à documentação da concepção de uma ideia, que é "visualizada" mentalmente pelo arquiteto e representada graficamente para que outras pessoas a compreendam. Essas representações iniciais são utilizadas pelo profissional para estudar a Arquitetura, quanto à sua forma, implantação e qualidade. Para os autores existe um fluxo contínuo entre ideia (imaginação), desenho (representação gráfica) e visualização, apresentados como processos interligados e dependentes entre si (Figura 01). Este ciclo representa a fase inicial da projetação, na qual o arquiteto detém a ideia e os processos para colocá-la no papel, sob a forma de desenho (BARR, JURICIC, 1994, apud BORGES, NAVEIRO, 2001), sendo importante esclarecer tais conceitos, aqui apresentados por meio de resumo do texto dos autores.

- Ideia/Imaginação - Elemento inicial da fase de concepção, fase em que o processo de compreensão do objeto arquitetônico se dá no pensamento do profissional; período de imaginação.

- Desenho/Representação gráfica - Elaboração de anotações gráficas derivadas dos pensamentos iniciais do profissional, a partir das quais são desenvolvidos desenhos com maior grau de precisão e 
número de detalhes cada vez maiores. Para tanto são utilizados volumes, formas, cores, texturas, transparência, enfim, diversos meios gráficos que preparam a base do projeto. Normalmente estes estudos preliminares assumem a forma de esboços, em sua grande maioria, elaborados à mão livre.

- Visualização - Tradução do projeto pelos interlocutores do arquiteto, etapa em que a representação atua como elemento de comunicação. Nesta fase o principal objetivo é apresentar o modelo gráfico ao público alvo que na maior parte dos casos são clientes (pessoas físicas que buscam um arquiteto para executar o projeto de sua edificação), mas também podem ser outros profissionais.

Figura 1: Esquema gráfico do ciclo de concepção e representação gráfica do projeto.

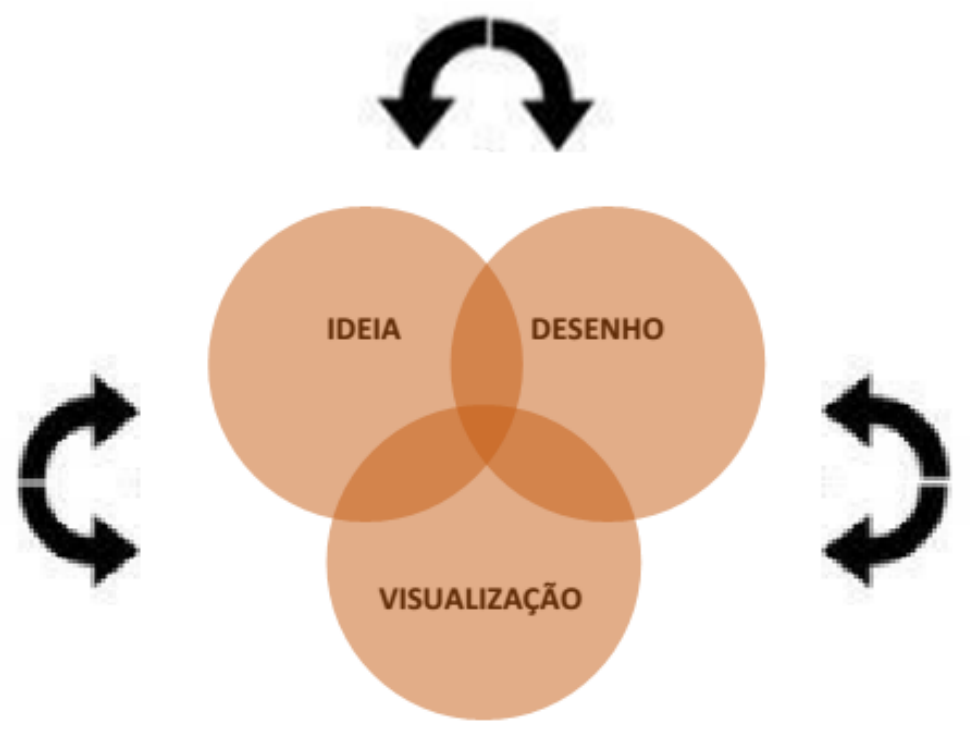

Fonte: Barr e Juricic (1994, apud BORGES, NAVEIRO, 2001), adaptado pela autora.

\section{MEIOS PARA COMUNICAR A IMAGEM}

Como expressão gráfica o desenho é um modo de comunicação muito mais efetivo do que conceitos ou explicações verbais (MOLES, 1974); isto é, uma teoria é melhor explicada quando aplicada a momentos práticos, visuais, concretos, condição que elucida, inclusive, a compreensão das obras de arte.

O conteúdo expressivo das obras de arte não se articula de maneira verbal, através de palavras, e sim de maneira formal, através de formas. São sempre as formas que se tornam expressivas. [...] Mas é justamente o caráter não-verbal da comunicação artística que constitui o motivo concreto da arte ser tão acessível e não exigir erudição das pessoas para ser entendida. Exige inteligência, sim, e sempre sensibilidade (OSTROWER, 1996, pg.23).

Sob esse ponto de vista, no campo da arquitetura a comunicabilidade do desenho deve ser entendida como um dos principais objetivos do profissional. Portanto, a linguagem usada para essa comunicação deve ser acessível a quem a observa ou analisa, de modo que na composição de sua representação, é preciso que existam elementos significativos da mensagem e facilmente reconhecíveis, como linhas, cores, contrastes e ritmos (OSTROWER, 1996).

Como a necessidade de interação entre arquitetos e leigos por meio do desenho é expressiva, precisando ter clareza e comunicar visualmente uma ideia, surgem perguntas como: Que caminho(s) visual(is) deve $(\mathrm{m})$ ser percorrido(s) para chegarmos a uma adequada interpretação do projeto? De que modo tornar a compreensão de um projeto acessível a qualquer pessoa sem exigir que ela $(\mathrm{s})$ tenha $(\mathrm{m})$ conhecimentos técnicos?

Embora esses questionamentos sejam amplos, e esse artigo não tenha a intenção de respondê-los diretamente, aponta-se a representação não-técnica (ou menos-técnica) como um caminho para facilitação deste processo comunicativo, argumento que pode ser comprovado a partir da obra de Lina Bo Bardi, sobretudo por meio dos croquis que a arquiteta utilizava para apresentar suas propostas projetuais.

\section{0 meio da comunicação é a mensagem}

Segundo Mcluhan (1974), a mensagem é a forma de comunicação introduzida na vida das pessoas para representar uma informação, que pode ser comunicada por diversos meios (linguagem escrita, falada, 
televisada, etc.); o importante é que o conteúdo seja expresso de forma objetiva. Não existem produtos ou meios de comunicação bons ou maus, melhores ou piores; é a forma como eles são empregados que determina seu valor (CARPENTER, MCLUHAN, 1968). O conteúdo é expresso em função da forma com ele é comunicado.

O conteúdo da escrita é a fala, assim como a palavra escrita é o conteúdo da imprensa e a palavra impressa é o conteúdo do telégrafo. [...] Qual o conteúdo da fala? [...] É um processo de pensamento, real, não-verbal em si mesmo (MCLUHAN, 1974, pg.22).

Em suma, na teoria da comunicação, o conteúdo é o fator principal utilizado pelos profissionais para veicular o produto ao observador, seja ele através de meios falados ou escritos, ou através de símbolos. Em ambos os casos o importante não é como o produto vai ser expresso, mas qual será o grau de seu entendimento (MOTTA, WEBER, FRANCA, PAIVA, 2002).

No campo da arquitetura, o conteúdo da mensagem é sintetizado por meio de sistemas de informações gráficas, ou seja, as ideias e conhecimentos técnicos do arquiteto são traduzidos através de meios de comunicação representados graficamente. Plantas baixas, croquis, elevações, perspectivas são todos meios de comunicação utilizados pelos profissionais para expressar um conteúdo. Aliás, em todos estes casos observa-se que o conteúdo é o mesmo (ou partes do mesmo), porém as formas de representação variam de acordo com a necessidade de expressão e comunicação.

\section{ANÁLISES DE REPRESENTAÇÕES GRÁFICAS EM LINA BO BARDI}

Com o propósito da aplicação desse tipo de estudo aos meios de representação e comunicação em arquitetura, serão analisadas algumas representações gráficas e não-técnicas de Lina Bo Bardi, isto é, obras que utilizam técnicas não-usuais para comunicar o projeto ao usuário. Ao invés de utilizar cotas, dimensões, escalas, representações com características desnecessárias ao leigo, as obras da arquiteta dão ideia de volume, profundidade, escala (noção clara da proporção), localização (relação da obra com outros objetos do entorno), opacidade, transparência, entre outros, como o uso de cores sob tons aquarelados criando uma linguagem visual própria.

As obras aqui apresentadas foram escolhidas sem preocupação com relevância arquitetônica, localização ou mesmo o ano em que foram projetadas. Os critérios utilizados para caracterização da imagem, foram determinados em função da expressividade e comunicação que ela representa, tais como: expressividade, linguagem visual; grafismo; transparência, opacidade, volume, cor, profundidade, claro-escuro, entre outros.

Destaque-se, antecipadamente, que nesse artigo as obras selecionadas e seus respectivos esquemas gráficos/visuais são representados por croquis esquemáticos da autora do artigo. Os desenhos originais da arquiteta são apresentados no compendio de Bardi (1993, organizado por Marcelo Ferraz) e podem ser consultados pelos interessados diretamente no acervo do Instituto Lina Bo e P. M. Bardi, disponível em http://www.institutobardi.com.br/busca_banco.asp.

\section{Edifício Diários Associados - Rua Álvaro de Carvalho, São Paulo, 1947}

A Figura 02 representa um croqui esquemático do desenho desenvolvido pela arquiteta Lina Bo Bardi referente ao estudo do hall principal do Edifício Diários Associados. Ele é caracterizado pelo uso da perspectiva, traço à mão livre, presença da Figura humana dando movimentação e humanização ao desenho; uso de transparência (sugerindo a ideia de vidro e de continuidade da visão para o exterior do edifício - como pode ser observado ao lado esquerdo da imagem), uso de cores e sugestão de um painel localizado do lado oposto ao de transparência. Apresenta, assim, elementos bastante característicos da perspectiva - grafismo à mão livre, com destaque para: uso de um ponto de fuga; ideia de continuidade do desenho; profundidade; uso da Figura humana para dar noção de proporção do espaço.

Com base na Figura 02 foi elaborada a Figura 02-A, que é um esquema gráfico ainda mais sintético, no qual destaca-se o ponto de fuga como elemento central e as linhas soltas e fluidas características da produção da arquiteta. 
Figuras 02 e 02-A: Croqui esquemático do hall principal e esquema gráfico visual.
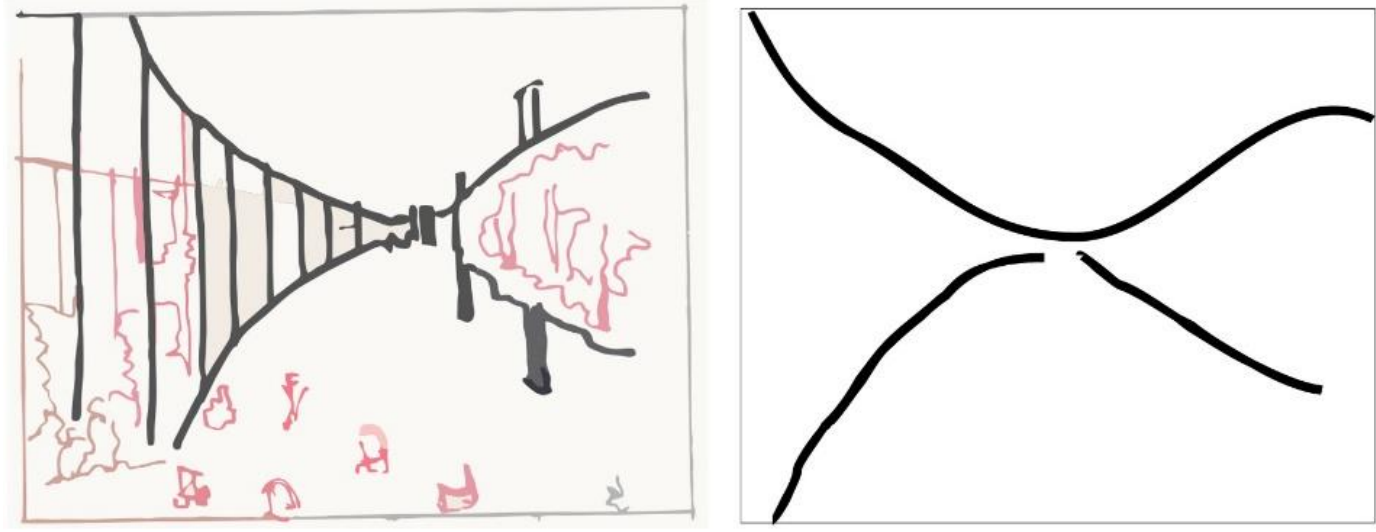

Fonte: SANTANA, Livia. 2017 e 2006, respectivamente.

Na Figura 03, tem-se o croqui esquemático referente ao estudo para o auditório do Edifício Diários Associados. A representação gráfica utilizada é bastante simbólica e representativa, utiliza-se de meios de expressão característicos de manchas, para destacar o entorno e focar no objeto - o auditório, a disposição dos assentos e níveis. Esta Figura simboliza o auditório de forma bastante expressiva, sem o uso de muitos detalhes.

Por sua vez, a Figura 03-A mostra um esquema gráfico desenvolvido a partir da Figura 03. Como destacado, as linhas são curvas, representando uma ideia perspectivada do objeto. A locação de uma Figura humana tem o objetivo de representar a visibilidade dele em direção ao palco. Em geral, a comunicação é feita pela sequência de linhas e a forma com que ela está representada graficamente.

Figuras 03 e 03-A: Croqui esquemático do estudo para auditório e esquema gráfico visual.
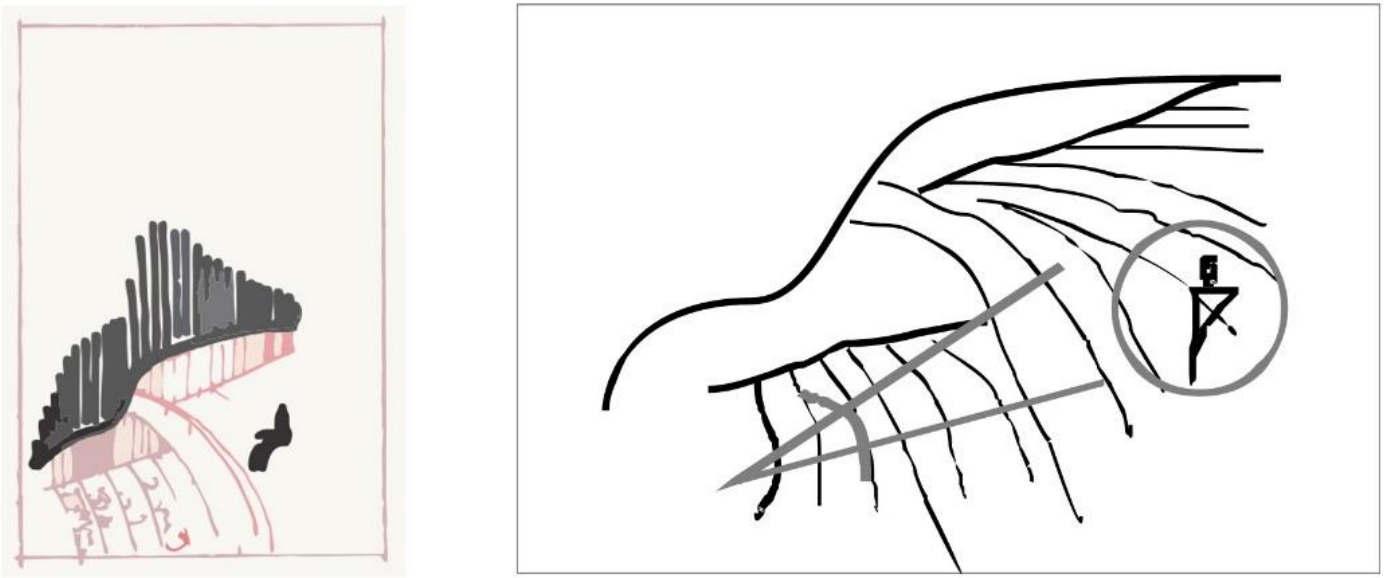

Fonte: SANTANA, Livia. 2017 e 2006, respectivamente.

\section{Espaços de Uso Público - Estudos: 1951}

Um croqui esquemático referente aos estudos para cinema popular é apresentado na Figura 04, que é caracterizada pelo uso da perspectiva isométrica, em que as duas direções planas estão projetadas a aproximadamente trinta e sessenta graus $\left(30^{\circ} \mathrm{e} 60^{\circ}\right)$ da linha horizontal. Está é uma forma bastante utilizada para representação de edificações externas. Note-se que estes estudos geralmente são rápidos e práticos, de modo que facilitam a concepção do projeto, tornando-se bastante representativos como meio de comunicação gráfico. A leitura feita pelo observador com base neles é bastante simples e rápida, pois a representação não possui elementos complexos. Neste exemplo, tem-se um edifício com eixo longitudinal, complementado por dois blocos laterais e uma estrutura de cobertura que estende até o piso, incluindo as paredes. Também caracteriza o desenho o uso de traços que representam a via de acesso ao edifício, situando-o dentro de um plano - terreno.

$\mathrm{Na}$ Figura 04-A tem-se um esquema gráfico marcado por linhas paralelas que representam o eixo de circulação longitudinal do edifício. Está representado também o local de acesso, que ocorre perpendicularmente a esse eixo principal, e, ainda, dois blocos anexos ao edifício. Em geral, a composição desta figura proporciona uma comunicação clara da proposta projetual, e a simbologia gráfica passa uma mensagem objetiva da funcionalidade do edifício analisado. 
Figuras 04 e 04-A: Croqui esquemático do estudo: cinema popular e esquema gráfico visual.
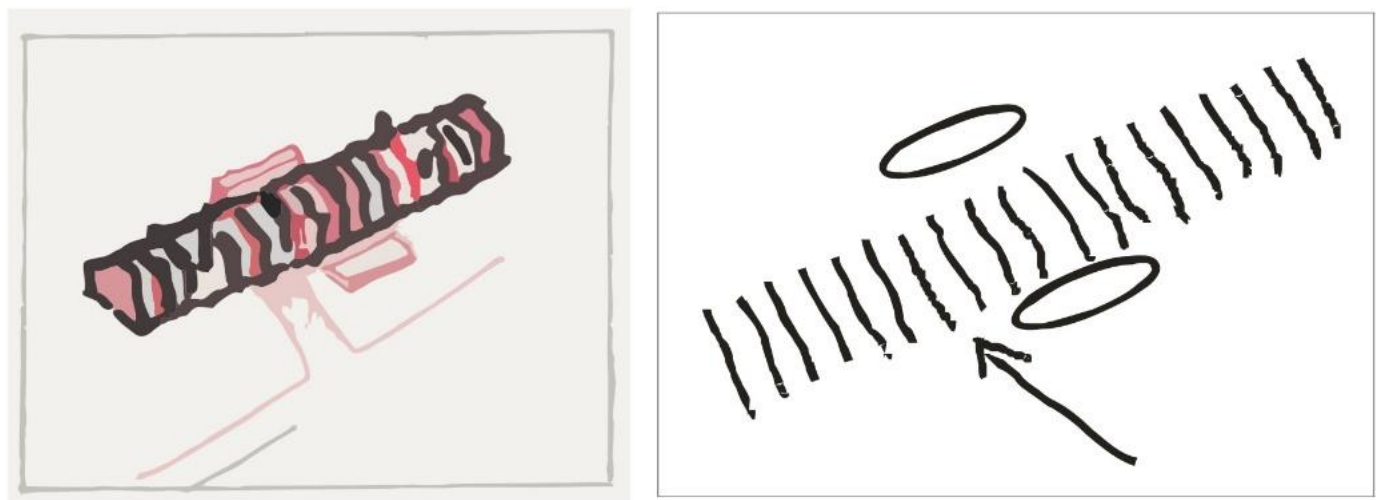

Fonte: SANTANA, Livia. 2017 e 2006, respectivamente.

Na Figura 05, o croqui esquemático destaca a representação gráfica a partir de desenhos planos, contendo uma planta baixa e um corte. Esta Figura tem como característica o uso de representações mais técnicas, contendo escala, dimensões e especificações. Apesar da representação do conteúdo consistir de grafismo exemplificado na forma plana e não perspectivada, não há interferência na tradução do projeto. Ou seja, a comunicação acontece da mesma forma, porém por representações diferentes.

Na Figura 05-A a representação dos traços característicos ocorre em função do uso do edifício, um cinema popular. Os traços enfileirados e paralelos a cada coluna representam os assentos do público. Ao fundo, a seta marca a entrada das pessoas no edifício, e à frente, o palco, representado por linhas inclinadas, indicando a direção do observador, quando sentados na plateia.

Figuras 05 e 05-A: Croqui esquemático do estudo: cinema popular e esquema gráfico visual.
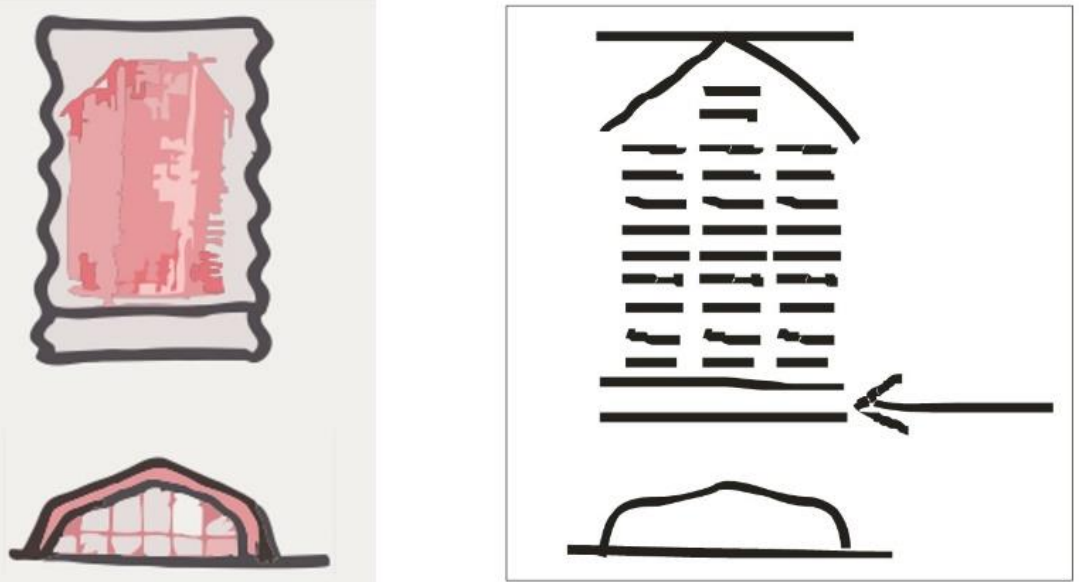

Fonte: SANTANA, Livia. 2017 e 2006, respectivamente.

\section{Museu de Arte de São Paulo (MASP) - Av. Paulista, São Paulo, 1957/1968}

A Figura 06 representa uma edificação de bastante destaque no contexto da cidade e marcante em termos visuais. Ela é caracterizada pelo uso da perspectiva para representação do edifício e seu entorno. Nota-se, em especial, a presença de cores, o movimento dos traços indicando a vegetação do entorno e uma abrangência de detalhes para simbolizar sua locação na quadra.

A forma do edifício é bastante simples, caracterizado por um eixo principal e sustentando por pilares que seguem o mesmo eixo. O volume é caracterizado pela opacidade e sensação de peso, em função do grande bloco. A leitura que se faz da representação gráfica é de um bloco único, retangular, ancorado por pilares e tendo como eixo principal, o longitudinal.

Na Figura 06-A, o esquema gráfico apresenta claramente o eixo principal do edifício e sua sustentação por pilares. As linhas paralelas entre si representam o volume único do edifício. As duas linhas mais grossas representam os pilares e dão sustentação às linhas perpendiculares. 
Figuras 06 e 06-A: Croqui esquemático MASP e esquema gráfico visual.
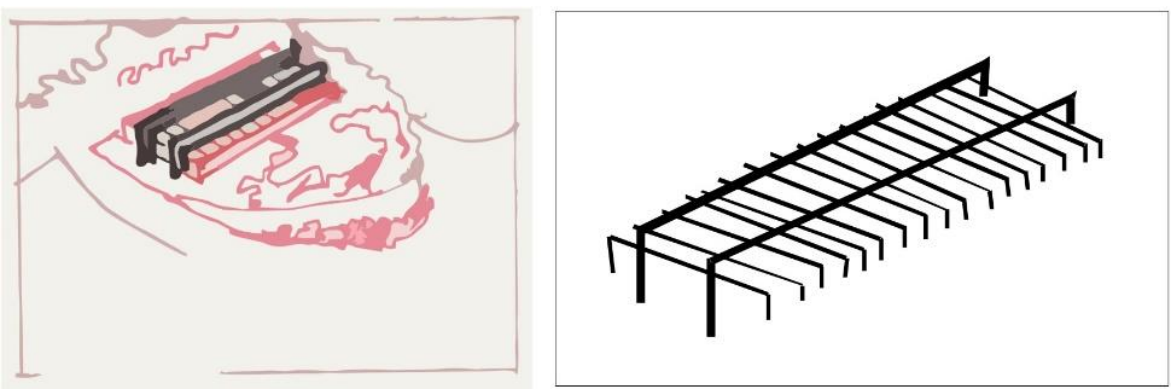

Fonte: SANTANA, Livia. 2017 e 2006, respectivamente.

Na Figura 07 tem-se um croqui esquemático referente à representação do corte longitudinal do MASP, apresentando o desnível do terreno e posicionamento da edificação no mesmo. Evidencia-se o uso de traços lineares marcantes, rígidos, simbolizando a forma do edifício. A representação utilizada é um meio mais técnico de comunicação. Na Figura 07-A o traço mais característico indica o perfil do terreno, sendo que, em função da sua inclinação foi distribuída a massa edificada que, representada por linhas paralelas, configuram um bloco único e sólido. Nessa proposta os acessos são claramente realizados por dois níveis: um localizado por baixo do bloco principal, e outro indicado no nível inferior.

Figuras 07 e 07-A: Croqui esquemático MASP e esquema gráfico visual.
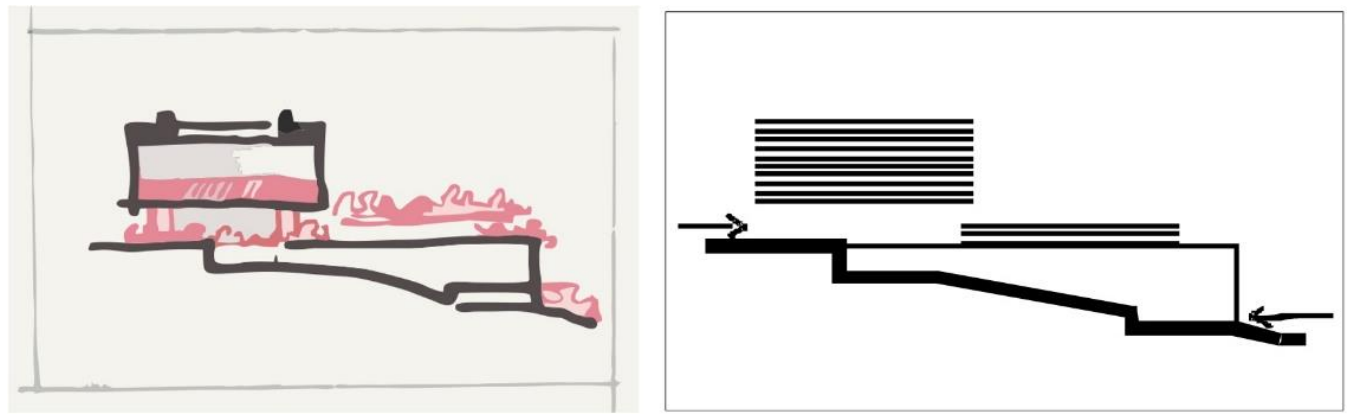

Fonte: SANTANA, Livia. 2017 e 2006, respectivamente.

\section{Casa Valéria P. Cirell - São Paulo, 1958}

O croqui esquemático referente a elevação da residência de Valéria $P$. Cirell encontra-se na Figura 08 , e que se caracteriza pelo uso de linhas verticais e representação de vegetação densa. O desenho desenvolvido por Lina Bo Bardi utiliza a técnica em aquarela para representação da vegetação; as cores de fundo são definidas por tons claros como o verde e azul, simbolizando um segundo plano: a vegetação.

O acesso principal à residência é marcado pelas portas, representadas graficamente com traços na vertical e horizontal, formando uma quadrícula e criando espaços vazios para não simular uma massa sólida e pesada em termos visuais. Em geral, é uma representação de fácil leitura.

A edificação interage com a vegetação e comunica com o observador devido a presença das cores, expressividade do desenho e linguagem visual. $O$ tratamento de cores dado ao plano de fundo facilita a visualização da edificação e permite que ela sobressaia, permanecendo em primeiro plano.

Na Figura 08-A o objetivo foi a caracterização dos planos de referência do desenho, primeiro composto pela cobertura da edificação; o segundo, pelo volume sólido; e o terceiro, pela vegetação.

Figuras 08 e 08-A: Croqui esquemático e esquema gráfico visual.
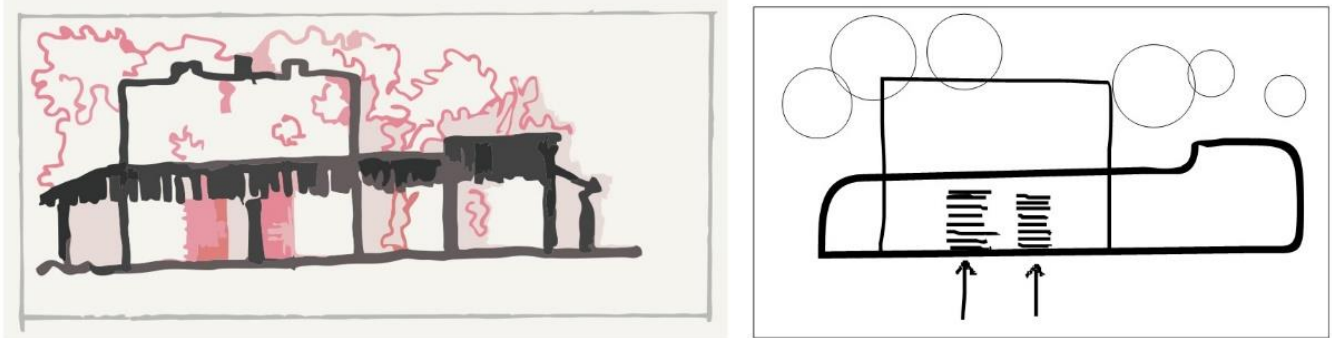

Fonte: SANTANA, Livia. 2017 e 2006, respectivamente. 


\section{Considerações sobre as representações em Lina Bo Bardi}

No trabalho de Lina Bo Bardi em geral, os desenhos configuram um contexto amplo de tipos variados de representações gráficas e a forma em que são representados os conteúdos são de fácil tradução e comunicação.

Suas representações caracterizam-se pelo marcante traço linear, uso da perspectiva, desenhos à mão livre, transparência, clareza do conjunto e beleza visual, como também, pelas proporções, presença de figuras humanas e uso de cores. $O$ traço dá leveza à obra, caracteriza e delimita o objeto representado graficamente. Os detalhes são "riscados" à parte, na maioria das vezes no mesmo papel, mas não interferem no objeto principal. Além disso especificações diversas (como: tipo de estrutura, dimensões e características técnicas dos materiais empregados), também fazem parte das representações, sem interferirem na linguagem visual.

\section{CONSIDERAÇÕES FINAIS}

O presente estudo evidencia a mensagem como o meio utilizado para realizar uma comunicação, quer ela aconteça pelo uso da fala, da escrita ou mesmo por meios advindos com a tecnologia. Para que a mensagem seja comunicada ao observador, o conteúdo (neste caso a ideia expressa no desenho), deve estar representado de forma clara e objetiva, possibilitando que o interlocutor (o cliente), receba e decodifique a comunicação e possa interagir com o comunicador.

Neste artigo, o trabalho de Lina Bo Bardi foi utilizado a fim de abordar meios não-técnicos utilizados pelos profissionais para se comunicarem com o cliente, além de investigar simbologias gráficas que podem ser utilizadas para veicular essa mensagem. Nos croquis da arquiteta as técnicas empregadas abrangem elementos visuais (como linha, superfície, volume, luz e cor) e características da obra em desenvolvimento (como transparência, opacidade, figuração humana, representação do entorno e localização), elementos presentes no conteúdo dos croquis de elevações, cortes, plantas e perspectivas.

Conclui-se que, como uma forma de comunicação, a representação gráfica possibilita a transmissão das ideias projetuais do arquiteto ao cliente, mas que isso não exige uma linguagem sofisticada; ao contrário, pode ser obtido por meio de recursos bastante simples, desde que dominados pelo profissional. A partir de croquis e perspectivas, a mensagem é comunicada ao observador. Com o uso de simbologias, representações e comunicação, é possível expressar o contexto da obra, suas características, enfim, todo um conjunto de significados que ela representa.

\section{REFERÊNCIAS}

BARDI, Lina Bo. Lina Bo Bardi. Instituto Lina Bo e P. M. Bardi. (Organizador: Marcelo Carvalho Ferraz). 1993. São Paulo.

BORGES, Marcos Martins; NAVEIRO, Ricardo Manfredi. Expressão gráfica e projetos de engenharia, arquitetura e desenho industrial: considerações acerca das formas tradicionais e recursos computacionais para a representação do projeto. Rev. Esc. Minas, v. 54, n. 1. Ouro Preto: Jan/Mar, 2001.

CARPENTER, Edmund; MCLUHAN, Marshall. Revolução na comunicação. Rio de Janeiro, Zahar Editores, 1968.

LARA, Fernando; MARQUES, Sônia (Orgs.). Projetar: desafios e conquistas da pesquisa e do ensino de projeto. Rio de Janeiro: EVC: Editora Virtual Científica, 2003.

MCLUHAN, Marshall. Os meios de comunicação como extensões do homem. São Paulo, Cultrix, 1974.

MOLES, Abraham Antoine. O cartaz (Coleção: Debates - Comunicação). São Paulo, Perspectiva, 1974.

MOTTA, Luiz Gonzaga; WEBER, Maria Helena; FRANCA, Vera; PAIVA, Raquel (Orgs.). Estratégias e culturas da comunicação. Brasília: Editora Universidade de Brasília, 2002 (Comunicação; v.I.).

OSTROWER, Fayga Perla. 1920 - Universos da arte. Rio de Janeiro: Campus, 1996.

NOTA DO EDITOR (*) O conteúdo do artigo e as imagens nele publicadas são de responsabilidade do(s) autor(es). 